\title{
Clinical Presentation, Outcomes, and Treatment of Membranous Nephropathy after Transplantation
}

\author{
Artur Q. B. da Silva $\left(\mathbb{D},{ }^{1}\right.$ Taina V. de Sandes-Freitas $\left(\mathbb{D},{ }^{2}\right.$ Juliana B. Mansur, ${ }^{1}$ \\ Jose Osmar Medicina-Pestana, ${ }^{1}$ and Gianna Mastroianni-Kirsztajn $\left(\mathbb{1}^{1}\right.$ \\ ${ }^{1}$ Federal University of São Paulo (UNIFESP), São Paulo, SP, Brazil \\ ${ }^{2}$ Federal University of Ceará (UFC), Fortaleza, CE, Brazil \\ Correspondence should be addressed to Gianna Mastroianni-Kirsztajn; giannamk@uol.com.br
}

Received 23 December 2017; Revised 20 May 2018; Accepted 12 June 2018; Published 5 July 2018

Academic Editor: Franca Anglani

Copyright (C) 2018 Artur Q. B. da Silva et al. This is an open access article distributed under the Creative Commons Attribution License, which permits unrestricted use, distribution, and reproduction in any medium, provided the original work is properly cited.

\begin{abstract}
There are scarce data about clinical presentation and outcomes of posttransplant membranous nephropathy (MN), and few reports include a large number of patients. This was a retrospective cohort including adult patients with posttransplant MN transplanted between 1983 and 2015 in a single center $(n=41)$. Only patients with histological diagnosis of MN in kidney grafts were included. Clinical and laboratory presentation, histological findings, treatment, and outcomes were detailed. Patients were predominantly male (58.5\%), with a mean age of $49.4 \pm 13.2$ years; 15 were considered as recurrent primary $\mathrm{MN}$; 3 were class V lupus nephritis; 14 were considered as de novo cases, 7 secondary and 7 primary $\mathrm{MN}$; and 9 cases were considered primary but it was not possible to distinguish between de novo $\mathrm{MN}$ and recurrence. Main clinical presentations were proteinuria (75.6\%) and graft dysfunction (34.1\%). Most patients with primary recurrent and de novo primary MN were submitted to changes in maintenance immunosuppressive regimen, but no standard strategy was identified; 31 patients presented partial or complete remission, and glomerulopathy appeared not to impact graft and patient survival.
\end{abstract}

\section{Introduction}

Membranous nephropathy (MN) is a common cause of nephrotic syndrome, and it is a prototype of autoimmune glomerular diseases [1]. In native kidneys, $\mathrm{MN}$ is more common in white men, adults in the fourth or fifth decade of life, and the elderly population [2]. It can be idiopathic in $70-80 \%$ of cases or secondary to infections (hepatitis B and C), drugs, neoplasia, systemic lupus erythematosus (SLE), and others [3]. Membranous nephropathy may occur in renal allografts as a recurrent or de novo disease [1]. Incidence of recurrent $\mathrm{MN}$ ranges from 10 to $45 \%$ and its impacts on transplants outcomes are controversial [4]. Recent findings in idiopathic $\mathrm{MN}$ suggest that in most patients the disease is caused by PLA2R autoantibodies. Such autoantibodies are involved in $50-60 \%$ of the cases of recurrent MN. Monitoring anti-PLA2R titers during follow-up helps to predict MN recurrence, and certain immunosuppressive treatments of anti-PLA2R positive patients may prevent recurrence $[5,6]$.
Nevertheless, this is not a marker that reveals the development of $\mathrm{MN}$ in all cases. It was already reported that some patients with anti-PLA2R antibodies at the time of transplantation would not develop MN recurrence [5, 7-9].

There are scarce data about clinical presentation and outcomes of posttransplant $\mathrm{MN}$, and few reports include a large number of patients. Thus, all additional information about this glomerulopathy can be useful in patient management. This study aimed to describe clinical, laboratorial, and histological characteristics, as well as treatment and outcomes of patients with posttransplant MN in a highvolume transplant center.

\section{Methods}

2.1. Design and Population. This retrospective cohort included adult patients with posttransplant $\mathrm{MN}$ transplanted between 1983 and 2015 in a single center that performs about 900 transplants per year. Only patients with histological 
diagnosis (optical microscopy and immunofluorescence) of MN in kidney grafts were included. Patients were identified through biopsies database and/or were selected from those followed in the Glomerulopathies Section. Protocol biopsies are not routinely performed in the center. Data were obtained from medical records and electronic databases. The study protocol was approved by the local Ethics Committee (CAAE: 24309913.1.0000.5505).

2.2. Definitions. Proteinuria was defined as urinary protein excretion superior to $0.3 \mathrm{~g}$ per day in a 24-hour urine collection or $0.3 \mathrm{~g} / \mathrm{g}$ in protein-to-creatinine ratio $(\mathrm{UPr} / \mathrm{Cr}$ ) determined in a random urine specimen [10].

Renal function was assessed by serum creatinine $(\mathrm{Cr})$ or by estimated glomerular filtration rate (eGFR) using 4variable MDRD formula [11]. The last observation carried forward (LOCF) adjustment was used for missing GFR values, attributing $10 \mathrm{~mL} / \mathrm{min}$ to patients who lost the graft and the last available value for those who died or lost followup. Baseline serum Cr was obtained by the average of last three measurements performed before posttransplant $\mathrm{MN}$ diagnosis. Graft dysfunction was defined as $\geq 50 \%$ or $\geq$ $0.3 \mathrm{mg} / \mathrm{dL}$ increase in baseline serum $\mathrm{Cr}$ confirmed in two different measurements.

Partial remission was defined as Cr stabilization in a value up to $25 \%$ above the baseline level associated with decrease of proteinuria by $50 \%$ or greater and $<3.0 \mathrm{~g} / \mathrm{g}$ when initial values were above $3.0 \mathrm{~g} / \mathrm{g}$. Complete remission was defined as serum Cr stabilization associated with proteinuria $<0.3 \mathrm{~g} / \mathrm{g}$ [12]. Spontaneous remission was defined as partial or complete remission without additional immunosuppressive treatment. All renal biopsies were processed according to standard techniques for light microscopy and immunofluorescence microscopy. Electron microscopy was not performed.

The immunosuppressive therapy was individualized according to our center protocols. Induction therapy, when indicated, consisted of anti-CD25 monoclonal antibodies or antithymocyte globulin; maintenance immunosuppression was based on calcineurin inhibitor (CNI, cyclosporine or tacrolimus) plus steroid and an antiproliferative drug (mycophenolate, azathioprine, or mTOR inhibitor).

2.3. Statistical Analysis. Categorical variables were expressed as frequency and percentages and compared using Chisquare or Fisher's exact test. Continuous variables were presented as mean and standard deviation (SD) and median when indicated; comparison between groups was performed using the Student's $t$-test. Survival analysis was obtained using the Kaplan-Meier method. Statistical analysis was performed using IBM SPSS ${ }^{\circledR} 22$ Statistics software, and p value was considered significant when $<5 \%$.

\section{Results}

3.1. Demographics. Between 1983 and 2015, 12,643 kidney transplants (KT) were performed and 41 patients with posttransplant $\mathrm{MN}$ were identified. Patients were predominantly male $(58.5 \%)$, with a mean age of $49.4 \pm 13.2$ years; $36.6 \%$ presented documented $\mathrm{MN}$ as chronic kidney disease etiology.
Most patients received kidneys from living donors (63.4\%) with a mean age of $38.1 \pm 16.3$ years.

Most patients received no induction therapy (78.1\%) and the initial maintenance immunosuppressive regimen was based on calcineurin inhibitor, steroid, and azathioprine in $56.1 \%$, in accordance with the transplant center protocol during the study period. More detailed information about demographics is available in Table 1.

3.2. Clinical Presentation. Fifteen cases were considered as recurrent primary $\mathrm{MN}$ as patients have chronic kidney disease (CKD) due to biopsy-confirmed MN; 3 were class $\mathrm{V}$ lupus nephritis: 2 of this had previous diagnosis of lupus and 1 was classified as unknown etiology for CKD; 14 had defined causes for renal disease and were considered as de novo cases: 7 showed an underlying cause for posttransplant $\mathrm{MN}$ and were considered as secondary (brain, uterus, anus, thyroid, and prostate neoplasias, hepatitis C, and hepatitis B) and 7 were primary posttransplant $\mathrm{MN}$; and 9 cases were considered primary but it was not possible to distinguish between de novo $\mathrm{MN}$ and recurrence, as patients had CKD for unknown or nonspecific chronic glomerulonephritis.

The most frequent initial manifestations of posttransplant $\mathrm{MN}$ were proteinuria $(75.6 \%, 3.2 \pm 1.2 \mathrm{~g})$ and graft dysfunction $(34.1 \%)$. Proteinuria $>0.3 \mathrm{~g} /$ day was observed at a median time of 40 months (ranging from 4 to 74) after KT. The mean levels of serum albumin and cholesterol were 3.4 $\pm 0.6 \mathrm{~g} / \mathrm{dL}$ and $198.8 \pm 58.6 \mathrm{mg} / \mathrm{dL}$, respectively. Compared to baseline values, eGFR decreased $26.8 \pm 16.4 \%$ at diagnosis. Diagnostic allograft biopsy was performed $3.7 \pm 2.5$ months after the onset of proteinuria and a median time of 41 months (ranging from 12.3 to 87.8) after KT. MN stage 2 was the main histological presentation $(60.9 \%)$, followed by stages 1 (24.4\%) and 3 (14.7\%) (Table 2).

3.3. Treatment. Patients with secondary posttransplant MN received renoprotection and treatment of underlying disease. Among patients with primary forms, 15 (45.5\%) received angiotensin-converting enzyme inhibitors (ACEI) and/or angiotensin II receptor blockers (ARB). Maintenance immunosuppressive regimen was modified in 20 of the 33 patients $(60.6 \%)$ with primary $\mathrm{MN}$ : 9 patients received high oral prednisone doses $(\geq 0.5 \mathrm{mg} / \mathrm{kg} /$ day $)$, with or without methylprednisolone pulse therapy; 4 patients were converted from azathioprine to mycophenolate; mTOR inhibitors were withdrawn in 3 patients, 2 of which were maintained temporarily on dual immunosuppressive regimen and 1 received mycophenolate instead; in 4 patients, modified Ponticelli regimen [14] was indicated, and antiproliferative drug was withdrawn. No patient received rituximab.

3.4. Outcomes. Fifteen patients had an apparently spontaneous remission. There were no significant differences between patients who presented spontaneous remission and those who did not remit or only remitted after immunosuppressive therapy concerning recipient age (47.6 \pm 14.7 versus $50.4 \pm 12.4$ years old, $\mathrm{p}=0.514$ ); donor source (living) (60 versus $65.4 \%, \mathrm{p}=0.749)$; time since $\mathrm{KT}$ at diagnosis $(36.8 \pm 38.7$ versus $62.9 \pm 56$ months, $\mathrm{p}=0.118)$; serum creatinine $(1.7 \pm 0.8$ 
TABLE 1: Demographic characteristics of patients with posttransplant MN.

\begin{tabular}{|c|c|}
\hline Variables & $\mathrm{N}=41$ \\
\hline Recipient gender - male, $\mathrm{n}(\%)$ & $24(58.5)$ \\
\hline Recipient age (years), mean \pm DP & $49.4 \pm 13.2$ \\
\hline Pretransplant dialysis, $\mathrm{n}(\%)$ & $40(97.5)$ \\
\hline Time on dialysis (months), mean $\pm \mathrm{DP}$ & $22.6 \pm 24.1($ median $=16)$ \\
\hline \multicolumn{2}{|l|}{ Etiology of end-stage renal disease, $\mathrm{n}(\%)$} \\
\hline Membranous nephropathy & $15(36.6)$ \\
\hline Lupus nephritis & $2(4.9)$ \\
\hline Unknown & $9(22)$ \\
\hline Chronic glomerulonephritis & $5(12.2)$ \\
\hline Hypertension & $5(12.2)$ \\
\hline Diabetes & $2(4.9)$ \\
\hline Chronic pyelonephritis & $1(2.4)$ \\
\hline Urological & $1(2.4)$ \\
\hline Cortical necrosis & $1(2.4)$ \\
\hline Panel reactive antibodies (\%), mean \pm DP & $7.85 \pm 22.6($ median $=0)$ \\
\hline \multicolumn{2}{|l|}{ Donor source, $\mathrm{n}(\%)$} \\
\hline Living & $26(63.4)$ \\
\hline HLA identical & $6(14.6)$ \\
\hline HLA haploidentical & $16(39)$ \\
\hline HLA distinct & $4(9.8)$ \\
\hline Deceased & $15(36.6)$ \\
\hline Standard criteria donor & $10(24.4)$ \\
\hline Expanded criteria donor ${ }^{1}$ & $5(12.2)$ \\
\hline Donor age (years), mean $\pm \mathrm{DP}$ & $38.1 \pm 16.3$ \\
\hline HLA mismatches, mean \pm DP & $2.3 \pm 1.8$ \\
\hline Cold ischemia time (hours), mean \pm DP & $25 \pm 9$ \\
\hline \multicolumn{2}{|l|}{ Induction therapy, $\mathrm{n}(\%)$} \\
\hline None & $32(78.1)$ \\
\hline Basiliximab & $1(2.4)$ \\
\hline Thymoglobulin & $8(19.5)$ \\
\hline \multicolumn{2}{|l|}{ Initial immunosuppressive regimen, $\mathrm{n}(\%)$} \\
\hline$C N I-P R E D-A Z A$ & $23(56.1)$ \\
\hline CNI-PRED-MPA & $14(34.1)$ \\
\hline CNI PRED-SRL & $4(9.8)$ \\
\hline
\end{tabular}

PRED: prednisone; CNI: calcineurin inhibitor; AZA: azathioprine; MPA: mycophenolic acid; SRL: sirolimus; HLA: human leukocyte antigens.

${ }^{1}$ United Network for Organ Sharing (UNOS) criteria [13].

versus $1.8 \pm 1.5 \mathrm{mg} / \mathrm{dL}, \mathrm{p}=0.835)$; proteinuria $(3.5 \pm 4.4$ versus $2.9 \pm 2.6 \mathrm{~g}, \mathrm{p}=0.613)$; posttransplant $\mathrm{MN}$ category (recurrence) (48.4 versus $20 \%, \mathrm{p}=0.152$ ); or maintenance immunosuppression with mycophenolate (34.6 versus $33.3 \%$, $\mathrm{p}=1.000)$.

Partial and complete remissions were observed in 25 $(61 \%)$ and $11(26.8 \%)$ patients, respectively, and occurred 358 \pm 180 days after diagnosis (Table 3 ). Patients who presented partial or complete remissions were younger $(46.8 \pm 12.3$ versus $57.3 \pm 13.2, \mathrm{p}=0.027$ ), a higher proportion received living donor transplants ( 74.2 versus $30 \%, \mathrm{p}=0.022)$, and a lower proportion was on mycophenolate $(22.6$ versus $70 \%$, $\mathrm{p}=0.017$ ) (Table 4).

One year after posttransplant $\mathrm{MN}$ diagnosis, proteinuria and serum creatinine were $2.6 \pm 3 \mathrm{~g} / 24 \mathrm{~h}$ and $2.2 \pm 1.1 \mathrm{mg} / \mathrm{dL}$, respectively. Adjusting for losses and deaths, mean eGFR was $34.2 \pm 18.7 \mathrm{~mL} / \mathrm{min}$ (Table 3). 1-, 3-, 5-, and 10-year patient survival was $97.5 \%, 94.7 \%, 88.3 \%$, and $88.3 \%$, respectively. Causes of death were infection $(n=2)$, cardiovascular event $(n=1)$, malignancy $(\mathrm{n}=1)$, and unknown $(\mathrm{n}=1)$. Death-censored graft survival at these periods was $95.1 \%, 86.9 \%, 86.9 \%$, and $68.4 \%$, respectively. Five of the 13 graft losses were attributed to posttransplant $\mathrm{MN}$, and the remaining 8 cases were due to unspecific interstitial fibrosis and tubular atrophy.

As expected, one year after posttransplant MN diagnosis, patients who presented partial or complete remission showed lower serum creatinine $(2.0 \pm 1.0$ versus $2.8 \pm 1.3 \mathrm{mg} / \mathrm{dL}$, $\mathrm{p}=0.049)$, higher eGFR $(41.8 \pm 18.9$ versus $27.0 \pm 12.9 \mathrm{~mL} / \mathrm{min}$, $\mathrm{p}=0.028)$, and lower proteinuria $(1.5 \pm 1.6$ versus $6.1 \pm 3.7$ $\mathrm{g}, \mathrm{p}<0.001)$. During the follow-up, there was a trend for a 
TABLE 2: Clinical presentation of patients with posttransplant MN.

\begin{tabular}{|c|c|}
\hline Variables & $\mathrm{N}=41$ \\
\hline Proteinuria $>0.3 \mathrm{~g} / \mathrm{g}$ or $\mathrm{g} / 24 \mathrm{~h}, \mathrm{n}(\%)$ & $31(75.6)$ \\
\hline Proteinuria $^{1}(\mathrm{~g} / \mathrm{g}$ or $\mathrm{g} / 24 \mathrm{~h})$, mean $\pm \mathrm{DP}$ & $3.2 \pm 1.2$ \\
\hline Time to onset of proteinuria $>0.3 \mathrm{~g} / \mathrm{g}$ or $\mathrm{g} / 24 \mathrm{~h}$ (months), mean $\pm \mathrm{DP}$ & $49.5 \pm 49.7($ median $=40)$ \\
\hline Serum albumin ${ }^{1}(\mathrm{~g} / \mathrm{dL})$, mean $\pm \mathrm{DP}$ & $3.4 \pm 0.6$ \\
\hline Serum total cholesterol ${ }^{1}(\mathrm{mg} / \mathrm{dL})$, mean $\pm \mathrm{DP}$ & $198.8 \pm 58.6$ \\
\hline Serum triglycerides ${ }^{1}(\mathrm{mg} / \mathrm{dL})$, mean $\pm \mathrm{DP}$ & $178.5 \pm 78.7$ \\
\hline Systolic blood pressure $^{1}(\mathrm{mmHg})$, mean $\pm \mathrm{DP}$ & $131 \pm 7.8$ \\
\hline Diastolic blood pressure $^{1}(\mathrm{mmHg})$, mean $\pm \mathrm{DP}$ & $82.2 \pm 6.5$ \\
\hline Graft dysfunction ${ }^{1}, \mathrm{n}(\%)$ & $14(34.1)$ \\
\hline Serum creatinine $^{1}(\mathrm{mg} / \mathrm{dL})$, mean $\pm \mathrm{DP}$ & $1.7 \pm 0.6$ \\
\hline $\mathrm{eGFR}^{1}\left(\mathrm{~mL} / \mathrm{min} / 1.73 \mathrm{~m}^{2}\right)$, mean $\pm \mathrm{DP}$ & $41.9 \pm 14.3$ \\
\hline eGFR decrease $^{1}(\%)$, mean \pm DP & $26.8 \pm 16.4$ \\
\hline Time between proteinuria and graft biopsy (months), mean \pm DP & $3.7 \pm 2.5$ \\
\hline Time between KT and graft biopsy (months), mean \pm DP & $53.4 \pm 51.5($ median $=41)$ \\
\hline \multicolumn{2}{|l|}{ Histological stages of $\mathrm{MN}, \mathrm{n}(\%)$} \\
\hline Stage 1 & $10(24.4)$ \\
\hline Stage 2 & $25(60.9)$ \\
\hline Stage 3 & $6(14.7)$ \\
\hline
\end{tabular}

eGFR: estimated glomerular filtration rate; KT: kidney transplant.

${ }^{1}$ At diagnosis.

TABle 3: Posttransplant MN outcomes.

\begin{tabular}{|c|c|}
\hline Variables & $\mathrm{N}=41$ \\
\hline Time on follow-up (months), mean \pm DP & $108.2 \pm 52.8$ \\
\hline Partial remission, n(\%) & $20(48.78)$ \\
\hline Complete remission, $\mathrm{n}(\%)$ & $11(26.8)$ \\
\hline Spontaneous remission, $\mathrm{n}(\%)$ & $15(36.6)$ \\
\hline Time to remission since diagnosis (days), mean $\pm \mathrm{DP}$ & $358 \pm 180$ \\
\hline Proteinuria $(\mathrm{g} / \mathrm{g} \text { or } \mathrm{g} / 24 \mathrm{~h})^{1}$, mean $\pm \mathrm{DP}$ & $2.6 \pm 3($ median $=2)$ \\
\hline Serum creatinine $(\mathrm{mg} / \mathrm{dL})^{1}$, mean $\pm \mathrm{DP}$ & $2.2 \pm 1.1$ \\
\hline $\mathrm{eGFR}\left(\mathrm{mL} / \mathrm{min} / 1.73 \mathrm{~m}^{2}\right)^{1}$, mean $\pm \mathrm{DP}^{1}$ & $38.2 \pm 19.5$ \\
\hline eGFR - LOCF $\left(\mathrm{mL} / \mathrm{min} / 1.73 \mathrm{~m}^{2}\right)^{1}$, mean $\pm \mathrm{DP}$ & $34.2 \pm 18.7$ \\
\hline
\end{tabular}

eGFR: estimated glomerular filtration rate; LOCF: last observation carried forward.

${ }^{1} 1$ year after diagnosis.

lower rate of deaths in patients who remitted (6.5 versus $30 \%$, $\mathrm{p}=0.083$ ), but the rate of graft loss was similar (35.5 versus $50 \%, \mathrm{p}=0.472$ ).

\section{Discussion}

This study evaluated demography, clinical and histological presentation, treatment, and outcomes of a relatively large cohort of patients with posttransplant $\mathrm{MN}$.

Unfortunately, a high proportion of patients did not have a confirmed diagnosis of chronic kidney disease (CKD) etiology (unknown and not defined chronic glomerulonephritis), which impairs the precise classification on recurrent and de novo cases. Besides, it is possible that some patients considered as having $\mathrm{CKD}$ due to hypertension actually have other underlying causes and that hypertension is secondary to renal disease.
More than a half of our cohort consisted of living donor transplants. This probably reflects the local practice in the early years of our transplant program, when living donor transplants were more common. The impact of the donor type on the risk of MN recurrence remains controversial [15].

Initial clinical and/or laboratorial presentation occurred late after $\mathrm{KT}$ and high proportion of patients presented nephrotic proteinuria, hypoalbuminemia, dyslipidemia, and graft dysfunction. Two patterns of $\mathrm{MN}$ recurrence were previously described [16]: "early recurrence" (within the first 6 months after KT), more common between living related donation, is generally oligosymptomatic, with mild proteinuria; on the other hand, "late recurrence" usually evolves with overt nephrotic syndrome. Since we did not perform protocol biopsies, even in the presence of isolated subnephrotic proteinuria, most of our cases were diagnosed in later stages. In this regard, we cannot rule out a higher 
TABLE 4: Risk factors for posttransplant MN remission.

\begin{tabular}{|c|c|c|c|}
\hline Variables & $\begin{array}{c}\text { Partial or complete } \\
\text { remission } \\
\mathrm{N}=31\end{array}$ & $\begin{array}{c}\text { No } \\
\text { remission } \\
\mathrm{N}=10\end{array}$ & p value \\
\hline Recipient age (years old), mean \pm DP & $46.8 \pm 12.3$ & $57.3 \pm 13.2$ & 0.027 \\
\hline $\begin{array}{l}\text { Time after KT at diagnosis (months), } \\
\text { mean } \pm \text { DP }\end{array}$ & $54.6 \pm 53.7$ & $49.4 \pm 46.4$ & 0.782 \\
\hline $\begin{array}{l}\text { Serum creatinine at diagnosis }(\mathrm{mg} / \mathrm{dL}) \\
\text { mean } \pm \text { DP }\end{array}$ & $1.6 \pm 0.7$ & $2.1 \pm 2.3$ & 0.351 \\
\hline $\begin{array}{l}\text { Proteinuria at diagnosis (g/24h or } \mathrm{g} / \mathrm{g}) \\
\text { mean } \pm \mathrm{DP}\end{array}$ & $2.9 \pm 3.2$ & $4.1 \pm 3.5$ & 0.337 \\
\hline Living donor, $\mathrm{n}(\%)$ & $23(74.2)$ & $3(30)$ & 0.022 \\
\hline RAAS blockade, $\mathrm{n}(\%)$ & $26(83)$ & $9(90)$ & 1.000 \\
\hline $\begin{array}{l}\text { Change in maintenance IS after } \\
\text { diagnosis, } \mathrm{n}(\%)\end{array}$ & $16(51)$ & $4(40)$ & 0.719 \\
\hline Treatment with high dose steroids, $\mathrm{n}(\%)$ & $14(45.2)$ & $3(30)$ & 0.480 \\
\hline Treatment with Ponticelli scheme, n(\%) & $1(3.2)$ & $2(20)$ & 0.142 \\
\hline
\end{tabular}

KT: kidney transplant; RAAS: renin angiotensin aldosterone system.

rate of subclinical $\mathrm{MN}$ recurrence in our patients, as renal biopsies were not always performed in the absence of overt proteinuria.

Regarding specific treatment, we observed a wide variety of approaches and a lack of standardization. This was probably due to the lack of a gold standard treatment for this glomerulopathy in KT recipients, who are already on immunosuppressive therapy. More recently, good results were described with the anti-CD20 rituximab for posttransplant $\mathrm{MN}$ treatment and prophylaxis. However, evidence is based on small sample size noncontrolled studies. Ideal dose and safety are important aspects to be evaluated [1618]. Noteworthy, rituximab is not available or reimbursed by Brazilian government for this off-label clinical indication.

As expected and widely reported for $\mathrm{MN}$ on native kidneys and allografts, about one-third of patients presented spontaneous remission $[17,19]$ and the majority of patients had complete or partial remission. The impact of posttransplant MN on allograft survival remains controversial [4]. In fact, in our study graft and patient survival were similar to those previously reported by our center [20-22].

Although the sample did not allow robust conclusions, we observed that remission rates were more frequent in younger recipients receiving living donor kidneys. Higher remission rates in younger patients were previously reported by studies on native kidneys [23]. However, to the best of our knowledge, there are no previous reports linking remission rates and donor source.

This study has some limitations that should be pointed out: (a) it is a single center, retrospective study, including patients transplanted in different decades; (b) it was not possible to estimate posttransplant $\mathrm{MN}$ incidence, since there was not a systematic recording or database for glomerular diseases in our center; (c) we did not assessed the antibodies against phospholipase A2 receptors (PLA2R) and thrombospondin type I domain-containing 7A (THSD7A), whose presence and intensity are related to recurrence; and (d) C4d was not routinely performed on graft biopsies. As strengths, this is a relatively large sample size, considering the low prevalence of the disease. Besides, the detailed description of diagnosis and treatment adds important information about the clinical management of such patients.

In summary late onset proteinuria, hypoalbuminemia, hypercholesterolemia, and graft dysfunction were the main clinical manifestations of posttransplant MN. RAAS blockade was common and there was not a standard treatment. The course was benign, with high proportion of remission rates and no impact on survival.

\section{Disclosure}

The data of this article has been presented as a poster at 54th ERA-EDTA Congress and it was published as abstract in Nephrology Dialysis Transplantation, Volume 32, Issue suppl_3, 1 May 2017, Pages iii503, https://doi.org/10.1093/ndt/ gfx165.MP205.

\section{Conflicts of Interest}

The authors declare that they have no conflicts of interest.

\section{Acknowledgments}

The authors are especially grateful to Professor Marcello Fabiano de Franco (in memoriam) for his invaluable contribution to Renal Pathology in Brazil. Artur Q. B. da Silva was supported by a CNPq grant during this study.

\section{References}

[1] P. A. Carmo, G. Mastroianni-Kirsztajn, W. B. Carmo, M. F. Franco, and M. G. Bastos, "Histopathological findings in elderly patients," Jornal Brasileiro de Nefrologia, vol. 32, no. 3, pp. 282287, 2010. 
[2] J. K. J. Deegens and J. F. M. Wetzels, "Membranous nephropathy in the older adult: Epidemiology, diagnosis and management," Drugs \& Aging, vol. 24, no. 9, pp. 717-732, 2007.

[3] R. J. Glassock, "The pathogenesis of idiopathic membranous nephropathy: a 50-year odyssey," American Journal of Kidney Diseases, vol. 56, no. 1, pp. 157-167, 2010.

[4] F. G. Cosio and D. C. Cattran, "Recent advances in our understanding of recurrent primary glomerulonephritis after kidney transplantation," Kidney International, vol. 91, no. 2, pp. 304314, 2017.

[5] A. Kattah, R. Ayalon, L. H. Beck Jr. et al., "Anti-phospholipase $\mathrm{A}_{2}$ receptor antibodies in recurrent membranous nephropathy," American Journal of Transplantation, vol. 15, no. 5, pp. 13491359, 2015.

[6] B. Seitz-Polski, C. Payré, D. Ambrosetti et al., "Prediction of membranous nephropathy recurrence after transplantation by monitoring of anti-PLA2R1 (M-type phospholipase A2 receptor) autoantibodies: A case series of 15 patients," Nephrology Dialysis Transplantation, vol. 29, no. 12, pp. 2334-2342, 2014.

[7] R. Stahl, E. Hoxha, and K. Fechner, "PLA2R autoantibodies and recurrent membranous nephropathy after transplantation," The New England Journal of Medicine, vol. 363, no. 5, pp. 496-498, 2010.

[8] L. F. Quintana, M. Blasco, M. Seras et al., "Antiphospholipase A2 receptor antibody levels predict the risk of posttransplantation recurrence of membranous nephropathy," Transplantation, vol. 99, no. 8, pp. 1709-1714, 2015.

[9] H. Debiec, L. Martin, C. Jouanneau et al., "Autoantibodies specific for the phospholipase A 2 receptor in recurrent and de novo membranous nephropathy," American Journal of Transplantation, vol. 11, no. 10, pp. 2144-2152, 2011.

[10] M.-P. M. Mayayo, M. Martinez Alonso, J. M. Valdivielso Revilla, and E. Fernández-Giráldez, "A new gender-specific formula to estimate 24-hour urine protein from protein to creatinine ratio," Nephron, vol. 133, no. 4, pp. 232-238, 2016.

[11] L. Czyżewski, J. Wyzgał, E. Czyżewska et al., "Performance of the MDRD, CKD-EPI, and cockcroft-gault formulas in relation to nutritional status in stable renal transplant recipients," Transplantation Proceedings, vol. 48, no. 5, pp. 1494-1497, 2016.

[12] B. Seitz-Polski, G. Lambeau, and V. Esnault, "Membranous nephropathy: Pathophysiology and history," Nephrol Ther, vol. 13, 1, pp. S75-S81, 2017.

[13] U.S. Health Resources and Services Administration United Network for Organ Sharing, "Policies and rationale for transplantation of organs for foreign nationals and exportation of organs outside the United States; general notice," Fed Regist, vol. 53, pp. 8977-8978, 1988.

[14] C. Ponticelli, P. Zucchelli, P. Passerini et al., "A 10-year follow-up of a randomized study with methylprednisolone and chlorambucil in membranous nephropathy," Kidney International, vol. 48, no. 5, pp. 1600-1604, 1995.

[15] G. Moroni, B. Gallelli, S. Quaglini et al., "Long-term outcome of renal transplantation in patients with idiopathic membranous glomerulonephritis (MN)," Nephrology Dialysis Transplantation , vol. 25, no. 10, pp. 3408-3415, 2010.

[16] B. Sprangers, G. I. Lefkowitz, S. D. Cohen et al., "Beneficial effect of rituximab in the treatment of recurrent idiopathic membranous nephropathy after kidney transplantation," Clinical Journal of the American Society of Nephrology, vol. 5, no. 5, pp. 790-797, 2010.

[17] A. Grupper, L. D. Cornell, F. C. Fervenza, L. H. Beck, E. Lorenz, and F. G. Cosio, "Recurrent membranous nephropathy after kidney transplantation: treatment and long-term implications," Transplantation, vol. 100, no. 12, pp. 2710-2716, 2016.

[18] Z. M. El-Zoghby, J. P. Grande, M. G. Fraile, S. M. Norby, F. C. Fervenza, and F. G. Cosio, "Recurrent idiopathic membranous nephropathy: early diagnosis by protocol biopsies and treatment with anti-CD20 monoclonal antibodies," American Journal of Transplantation, vol. 9, no. 12, pp. 2800-2807, 2009.

[19] T. S. Dabade, J. P. Grande, S. M. Norby, F. C. Fervenza, and F. G. Cosio, "Recurrent idiopathic membranous nephropathy after kidney transplantation: A surveillance biopsy study," American Journal of Transplantation, vol. 8, no. 6, pp. 1318-1322, 2008.

[20] J. O. Medina-Pestana, N. Z. Galante, H. Tedesco-Silva Jr. et al., "Kidney transplantation in Brazil and its geographic disparity," Jornal Brasileiro de Nefrologia, vol. 33, no. 4, pp. 472-484, 2011.

[21] J. Medina Pestana, "Excellence and efficiency through a structured large scale approach: the hospital do rim in São Paulo, Brazil," Transplantation, vol. 101, no. 8, pp. 1735-1738, 2017.

[22] D. B. Cordeiro Cabral, T. V. de Sandes-Freitas, J. O. MedinaPestana, and G. Mastroianni-Kirsztajn, "Clinical features, treatment and prognostic factors of post-transplant immunoglobulin a nephropathy," Annals of Transplantation, vol. 23, pp. 166175, 2018.

[23] N. Polanco, E. Gutiérrez, F. Rivera et al., "Spontaneous remission of nephrotic syndrome in membranous nephropathy with chronic renal impairment," Nephrology Dialysis Transplantation , vol. 27, no. 1, pp. 231-234, 2012. 


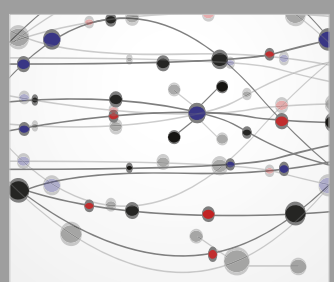

The Scientific World Journal
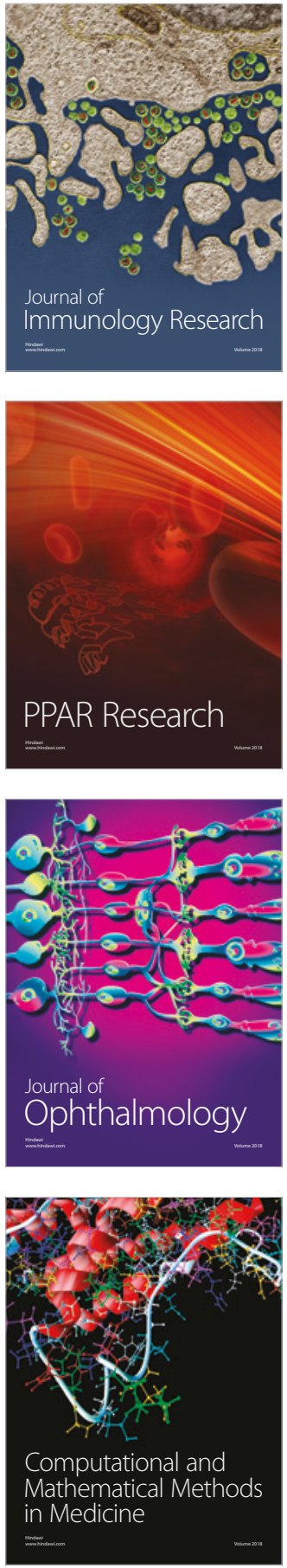

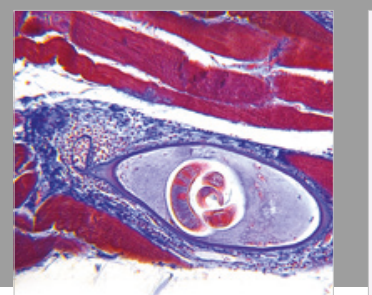

Gastroenterology Research and Practice

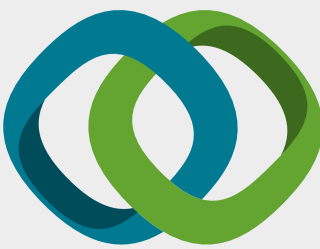

\section{Hindawi}

Submit your manuscripts at

www.hindawi.com
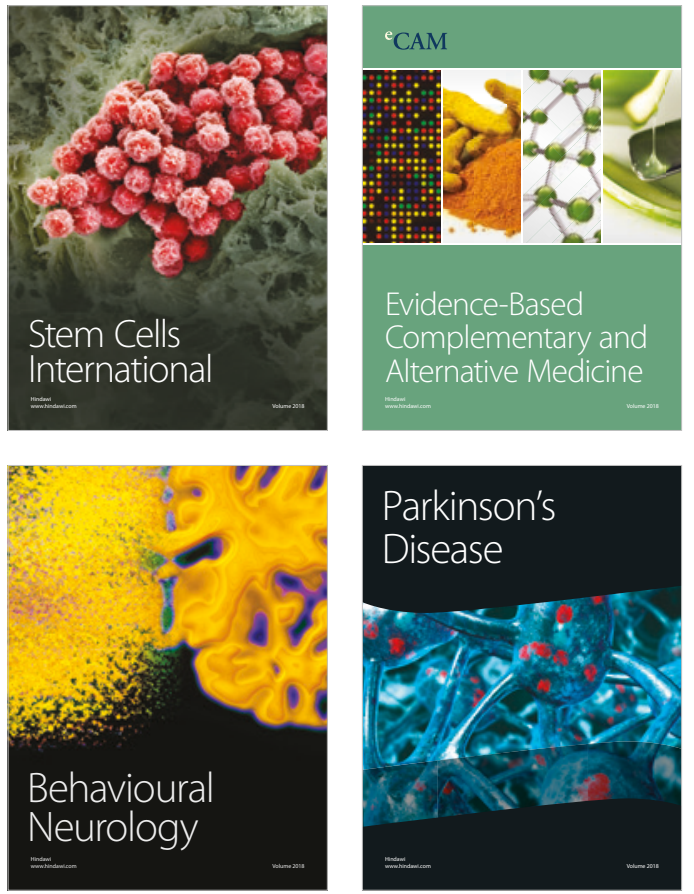

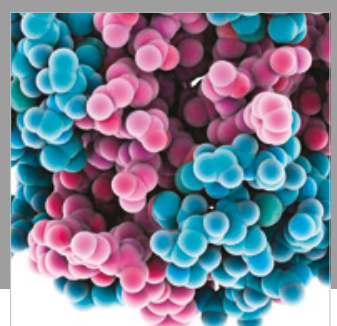

ournal of

Diabetes Research

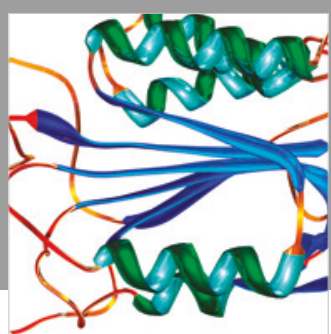

Disease Markers
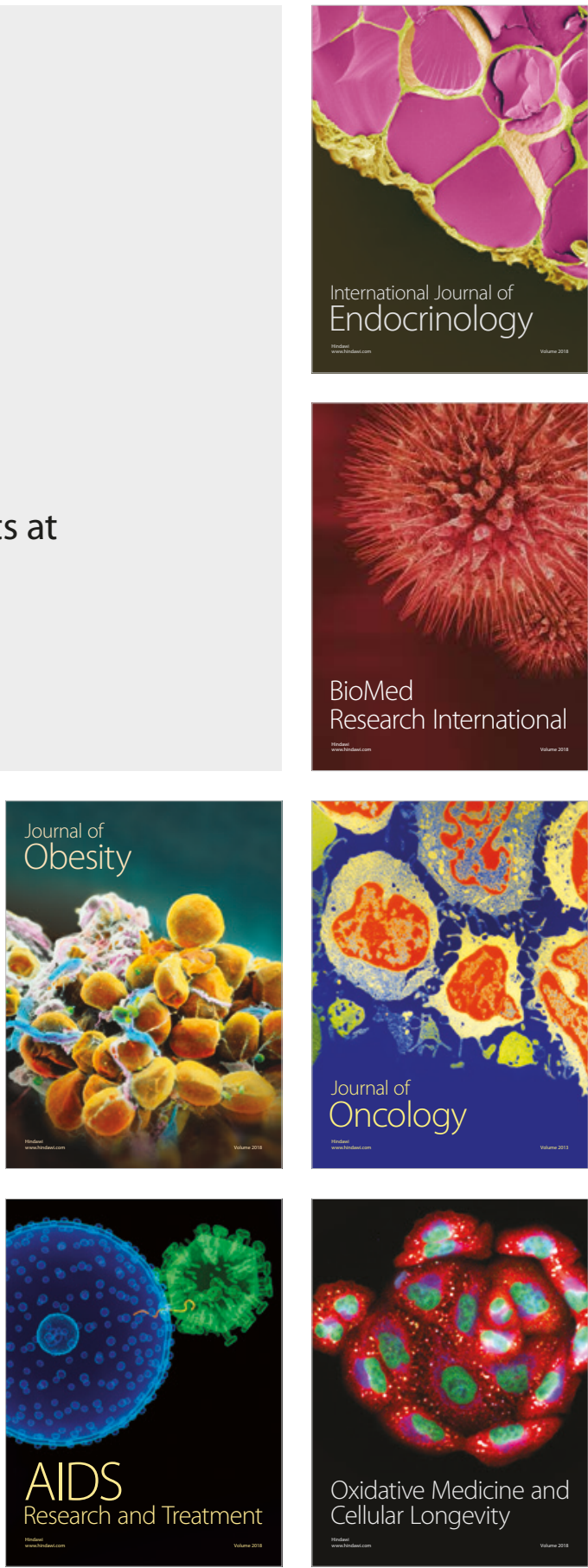